\title{
COMPARISON STUDY OF HAIR TONIC AND GEL FORMULATION OF ANGIOPTERIS EVECTA AS A HAIR GROWTH STIMULANT
}

\section{RESMI MUSTARICHIE, DOLIH-GOZALI, SETTINGS IMAM ADI WICAKSONO, FERIS DZAKY RIDWAN NAFIS}

\author{
Universitas Padjadjaran, Hegarmanah, Jatinangor, Kabupaten Sumedang, Jawa Barat 45363, Indonesia
}

Email: resmi.mustarichie@unpad.ac.id

Received: 14 Mar 2019, Revised and Accepted: 10 May 2019

\section{ABSTRACT}

Objective: Previous research has proven that the water fraction of the Angiopteris evecta root has hair growth activities. The objective of this research was to determine the formula of gel and hair tonic preparations of pakis munding (Angiopteris evecta L.) which met the requirements as a pharmaceutical preparation, good and effective in stimulating hair growth.

Methods: Formulation of hair tonic and gel preparations were made using 7.5, 10.0, and $12.5 \%$ of $A$. Evecta root water extracts as active compounds. The formulation of the two preparations was based on the standard formulation method. The evaluation and formulation test were carried out by organoleptic examination and homogeneity, $\mathrm{pH}$, viscosity, scattering power test, stability test, and safety test based on the standard preparations including Indonesian pharmacopeia. Statistical tests were carried out on both formulas against rabbits based on the modification of the Tanaka method. Comparison of statistics on both formulas was also carried out.

Results: It was found both formulas fulfill standard requirements as pharmaceutical preparations. Statistically, the best activity in hair tonic preparations was at a concentration of $12.5 \%$ and for gels at a concentration of $10.0 \%$ ethanol extract seen from measurements of hair length. Statistically, using the Independent T-test to find out the significant differences in the average hair length on hair tonic and gel, it was found there was no significant difference between the two formulas. It was found that the best formula for hair tonic and gel was in the addition of $10.0 \%$ and $12.5 \%$ extracts, respectively.

Conclusion: The results obtained in this research work clearly indicated that both hair tonic and gel formulas of $A$. evecta root water extract may be used as stimulating hair growth.

Keywords: Hair growth stimulant, Angiopteris evecta, Hair tonic, Gel, Pharmaceutical preparations

(C) 2019 The Authors. Published by Innovare Academic Sciences Pvt Ltd. This is an open access article under the CC BY license (http://creativecommons.org/licenses/by/4.0/) DOI: http://dx.doi.org/10.22159/ijap.2019v11i4.33071

\section{INTRODUCTION}

To overcome baldness, various methods are carried out, one of which is the innovation of synthetic hair growth formula and herbal products. The use of these types of material has been widely produced, so in the market today there are many hair growth drugs. The use of synthetic materials in cosmetics has been greatly reduced because there are dangerous side effects. For example, minoxidil which is used topically on the scalp usually causes itching on the scalp, irritation, and allergies [1]. The examples of herbal plants that have hair growth activities are algae extract, ginkgo biloba, the green, saw palmetto, stinging nettle [2] as well as Angiopteris evecta) [3] and Sauropus androgynous [4].

Based on the research conducted Mustarichie et al. [5] pakis munding (Sundanese) roots have activities to grow hair. Judging from the ethanol extract with a concentration of $10 \% ; 20 \% ; 40 \%$ and $20 \%$ water extract; $40 \%$ have better results in growing rabbit hair compared to positive controls (Minoxidil). Tresnawati [6] mentioned that pakis munding roots contain flavonoids, saponins, polyphenols, tannins, quinones, monoterpenes and sesquiterpenes and water fraction with a concentration of $7.5 \%, 10 \%$, and $12.5 \%$ having the good hair growth activity.

In practice, people tend to use cosmetic products that are easy to use, such as gel and hair tonic. Hair tonic has been used by Native Americans to overcome baldness using several species of plants [7]. The use of hair tonic has advantages as easy and suitable for use on the scalp, both in trans-appendageal absorption, easily spread, not greasy, and does not leave residues on the scalp that can cause irritation [8]. A gel is a preparation that is easier to formulate than other semisolid preparations and has good dispersion [9]. The gel is also easy to wash and not sticky. Besides this gel preparation is not easy to cause irritation and allergies [10].

This research reports on the hair tonic formula and gel of the $A$. evecta water fraction and their activity as a stimulator of hair growth as well as statistically the most effective preparation between gel and hair tonic in stimulating hair growth.

\section{MATERIALS AND METHODS}

\section{Materials}

The materials used in this study were pakis munding roots obtained from Mount Galunggung Tasikmalaya and determined at the Laboratory of Taxonomy, Biology Department, Faculty of Mathematics and Natural Sciences, Universitas Padjadjaran.

\section{Methods}

The research methods included material collection, determination, material processing, ethanol extract quality test, making water fraction from ethanol extract, phytochemical screening, gel preposition and hair tonic from water fraction, fraction gel and hair tonic formulations from fractions water, evaluation of gel and hair tonic preparations, testing of the most active hair growth stimulant activity from gel and hair tonic preparations, gel irritation tests and hair tonic preparations, and analysis using statistical methods

\section{Plant material processing}

After the pakis munding root part was separated, then washed by brushing thoroughly. Then drain so that the remaining washing water was lost. After drying, the root was then cut, until a small size was obtained and dried by air at room temperature referred to How to make a simplicial method [11].

\section{Extractions}

The simplicial was extracted using the maceration method using $70 \%$ ethanol as its solvent based on modification method of Kusuma et al. [12]. The extract was concentrated using a rotary evaporator at a temperature of $40-50{ }^{\circ} \mathrm{C}$ and continued by using a water bath at a temperature of $40-50{ }^{\circ} \mathrm{C}$ to obtain a dried extract with a constant 
weight. The parameter extract was analyzed it's organoleptic including shape, smell, color, and taste and water content referring to Indonesian Pharmacopeia [13].

\section{Phytochemical screening}

Phytochemical screening was carried out to determine the content of secondary metabolites guidance by Farnsworth method [14]. This test included: Flavonoid Test, the $0.5 \mathrm{~g}$ fraction was added to a cup and then added with $2 \mathrm{ml}$ of $70 \%$ ethanol then stirred. Then added a number of $0.5 \mathrm{~g}$ magnesium powder and also dripped 3 drops of concentrated $\mathrm{HCl}$. The appearance of red color to purplish red is a sign of flavone; Alkaloid Test, a number of fractions of $0.5 \mathrm{~g}$ were carried out by $2 \mathrm{~N} \mathrm{HCl}$. Then the acid layer was separated into three parts. The first part was used for blank, the second part was added dragendorff reagent and observed whether there was a deposit that has a brown-orange color. The third part was added to the major reagent and the presence of white deposits became a positive sign of the alkaloid compound; Saponin Test, a number of fractions of $0.5 \mathrm{~g}$ were dissolved using distilled water and then left for fifteen minutes and then shaken for ten seconds. If there was a stable froth for about 10 min then the froth remains when adding $2 \mathrm{~N} \mathrm{HCl}$, then a positive sample contains saponin; Tanin Test, a number of fractions of $0.5 \mathrm{~g}$ were dissolved in $50 \mathrm{ml}$ hot water and then boiled in $15 \mathrm{~min}$, then cooled and filtered. The filtrate was given $1 \%$ gelatin. Signs of tannins when white deposits are formed; Polyphenol Test, a number of $0.5 \mathrm{~g}$ fractions were first dissolved in some water in the test tube. The test tube was then heated, then the solution was filtered while still hot. The filtrate that had been obtained then drops a number of solutions of iron (III) chloride. A sign of the presence of polyphenol compounds when black blue color was formed; Test Monoterpenes and Sesquiterpenes, some $0.5 \mathrm{~g}$ fractions were extracted with ether, then evaporation was carried out using a vaporizer dish until the fraction dried. The resulting residue was then dripped with vanillin sulfate reagent. Signs of the presence of monoterpenoid and sesquiterpenoid compounds in the sample when colors were formed; Steroid and Triterpenic Tests, a number of fractions of $0.5 \mathrm{~g}$ were searched using ether, then evaporation was carried out using a vaporizer plate until the fraction dried. The residue was then given a few drops of Lieberman Burchard reagent. The presence of purple indicated that the sample contains compounds from the triterpenoid group, whereas if there was a blue-green color it was a sign of compounds from the steroid group; Quinone Test, a number of $50 \mathrm{mg}$ fractions are dissolved in $50 \mathrm{ml}$ of hot water, then simmer for about 15 $\mathrm{min}$, then cooled and filtered. The filtrate was given a number of $\mathrm{NaOH}$, a sign of quinone compounds when yellow to red was formed.

\section{Hair tonic and gel formulation}

Two types of formulas were made using the different variation composition of the water extract of pakis munding, as shown in table 1 and 2. Formulation referred to cosmetic textbook $[10,15,16]$

Table 1: Pakis munding water faction gel formula

\begin{tabular}{lllll}
\hline Materials & \multicolumn{2}{l}{ Quantity } & & \\
\cline { 2 - 5 } & I & I $/ \mathbf{w})$ & III & IV \\
\hline Pakis munding water fraction & 7.5 & 10.0 & 12.5 & - \\
Carbopol 940 & 1.0 & 1.0 & 1.0 & 1.0 \\
Methylparaben & 0.2 & 0.2 & 0.2 & 0.2 \\
Propylparaben & 0.02 & 0.02 & 0.02 & 0.02 \\
Glycerin & 10.0 & 10.0 & 10.0 & 10.0 \\
Na2EDTA & 0.03 & 0.03 & 0.03 & 0.03 \\
Triethanolamine & qs & qs & qs & qs \\
Aquadest ad100 & qs & qs & qs & qs \\
\hline
\end{tabular}

Notes: qs = quantum satis (Latin, a pharmaceutical term for sufficiently)

Table 2: Pakis munding water faction Hair tonic formula

\begin{tabular}{lllll}
\hline Materials & Quantity (\% w/w) & & \\
\cline { 2 - 5 } & I & II & III & IV \\
\hline Pakis munding water fraction & 7.5 & 10.0 & 12.5 & - \\
Ethanol 96\% & 40.0 & 40.0 & 40.0 & 40.0 \\
Propyleneglycol & 2.0 & 2.0 & 2.0 & 2.0 \\
Methylparaben & 0.075 & 0.075 & 0.075 & 0.075 \\
propylparaben & 0.02 & 0.02 & 0.02 & 0.02 \\
Sodium metabisulphite & 0.2 & 0.2 & 0.2 & 0.2 \\
Aquadest ad 100 & qs & qs & qs & qs \\
\hline
\end{tabular}

Notes: qs = quantum satis (Latin, a pharmaceutical term for sufficiently)

\section{Evaluation of gel and hair tonic formula}

Gel Evaluations included Organoleptic examination and homogeneity, pH, viscosity, spreadability, and stability. For the Hair tonic formula, evaluations included Organoleptic examination and homogeneity, $\mathrm{pH}$, viscosity, and stability.

\section{Test hair growth activity of gel and hair tonic}

Testing of hair growth stimulant activity for gel and hair tonic preparations for pakis munding roots was carried out on 8 male rabbits aged 4-5 mo, healthy without defects and having a body weight of 2-2.5 Kg. Ethical approval no 1401/UN6. KEP/PEC/2018 was issued by the Research Ethics Committee-Universitas Padjadjaran for this work. This test followed the modification of Tanaka et al. methods [17].

\section{Dermal acute irritation test gel and hair tonic preparations}

The dermal acute irritation test was a test on animals (albino rabbits) with the aim of detecting toxic effects that appear after exposure to the preparation for $3 \mathrm{~min}$ to $4 \mathrm{~h}$. The principle of this method was that the preparations be exposed to a single dose test preparation on animal skin with areas of skin that were not treated as controls. The degree of irritation was assessed at $1,24,48$, and 72-time intervals after exposure to the test preparation [18].

\section{Statistical analysis}

The results of measurements of rabbit hair length obtained were then averaged. Normality test using the Shapiro Wilk method and the Levene method's homogeneity and then the data is processed using the statistical method Kruskal Wallis $[19,20]$.

\section{RESULTS AND DISCUSSION}

\section{Plant determination}

Plant determination was carried out at the Laboratory of Plant Taxonomy, Department of Biology, Faculty of Mathematics and Natural Sciences. The results of plant determination, Plant Identification sheet 
no. 499/HB/02/0-17 showed that the Family was Marattiaceae, genus Angiopteris, and species Angiopteris evecta (G. Forst.) Hoffm.

\section{Extraction results}

The extracted results obtained a dry extract with a yield of $12.6 \%$ $\mathrm{w} / \mathrm{w}$ and the results of observations of organoleptic were in the form of dry powder, blackish brown color, and distinctive smelling simplicia.

\section{Phytochemical screening}

Phytochemical screening results can be seen in table 3.

\section{Examination of moisture content}

The measurement of the water content has the purpose of providing a range of the amount of water contained in the material and knowing the quality of the extract. The results of the water content, which was $0.2 \mathrm{ml}$ from 2 grams of extract, meant that the value of the moisture content was $10 \%$ and still met the requirements of water content which was below $10 \%$ [13]. It meant that the extracts of pakis munding obtained met the specified standards so that the storage period will be relatively stable. If the extract had a low water content, it would minimize the risk of developing microorganisms in the extract and avoid the degradation of the active compound metabolism of microorganisms.

Table 3: Secondary metabolites of $A$. evecta

\begin{tabular}{lll}
\hline No & Secondary metabolites & Extract \\
\hline 1 & Alkaloids & - \\
2 & Flavonoids & + \\
3 & Quinone & + \\
4 & Monoterpenoids and Sesquiterpenoids & + \\
5 & Polyphenol & + \\
6 & Saponins & + \\
7 & Steroids and Triterpenoid & - \\
8 & Tannin & + \\
\end{tabular}

Notes: $+=$ detected; $-=$ not detected, this result similar to our previous report [3] in which we reported the secondary metabolites of Pakis munding simplicia and its ethanol extract.

\section{Fractionation of ethanol extract}

The fractionation process was a process carried out with the aim of separating compound components based on certain properties, namely based on their polarity. The fractionation method used is by the liquid-liquid extraction method (LLE) [21]. The principle of separation of compounds with liquid-liquid extraction was like dissolve like where compounds that had the same polarity would be attracted or carried away with compounds that had the same level of polarity. The solvent used was a solvent that has a different level of polarity so it would not be mixed, namely water, $n$-hexane, and ethyl acetate. Non-polar compounds would be attracted to n-hexane, semipolar compounds would be attracted to ethyl acetate, and polar compounds would be attracted to water. In this study 315 grams of a thick extract of pakis munding roots were fractionated with a ratio of extract: solvent $(1: 10)$ to obtain a water fraction.

\section{Gel and hair tonic formulation}

The hair tonic formula can be seen in table 2 and 3. For Gel preparations, first Carbopol 940, Methylparaben, Propylparaben, and EDTA were dispersed on some distilled water $40{ }^{\circ} \mathrm{C}$ with constant stirring for $30 \mathrm{~min}$ then this dispersion was stored first for $24 \mathrm{~h}$ to fully expand [22]. Furthermore, the water fraction of pakis munding was dissolved in some distilled water and then added with glycerin. The two mixtures above were then mixed in beaker glass and TEA was added to stabilize the $\mathrm{pH}$ [23]. Carbopol ${ }^{\circledR} 940$ polymer was a white powder, crosslinked polyacrylic acid polymer. It was an extremely efficient rheology modifier capable of providing high viscosity [24]. Methylparaben [25] and propylparaben [26] were used as a preservative. Glycerin [27] was used as a moisturizer to treat or prevent dry, rough, scaly, itchy skin and minor skin irritations. The use of the chelating agent ethylenediaminetetraacetic acid (EDTA) was widespread in the pharmaceutical industry. It was used as a treatment of heavy metal poisoning as well as an antioxidant in many pharmaceutical preparations [28]. Triethanolamine in Gel was used as a buffering agent, masking and fragrance ingredient, and surfactant, in addition to its primary use as a $\mathrm{pH}$ adjuster [29].

For Hair tonic preparations, nipagin and nipasol were first dissolved in $50 \%$ ethanol, and sodium metabisulphite was dissolved in distilled water. Then the two phases were mixed using a stirrer. Then the fraction of water that had been dissolved with distilled water was entered into the initial mixture slowly while still stirring with the stirrer. Finally, propylene glycol was added and stirred with a stirrer until homogeneous [30].

\section{Evaluation of hair tonic and gel}

The results of observations of organoleptic, pH, stability, viscosity and dispersion were shown in table 4. Organoleptic Observation was made on formulas in the form of odor, color, and physical homogeneity [22, 31]. $\mathrm{pH}$ testing using universal $\mathrm{pH}$ paper or $\mathrm{pH}$ meters. 1 gram of gel preparation into $100 \mathrm{ml}$ of distilled water, each formula was done triple and the average was searched. The standard $\mathrm{pH}$ of the scalp was around 4.5-6.5 [32]. Stability test using the freeze-thaw method, where the sample underwent a freeze and thaw cycle for $12 \mathrm{~d}$ with 6 cycles. Each cycle consisted of storage at $4{ }^{\circ} \mathrm{C}$ and $45^{\circ} \mathrm{C}, 24 \mathrm{~h}$ each [22]. The viscosity test of the preparation was determined using a Brookfield viscometer; the test for Gel was carried out using number 4 spindle and $2 \mathrm{rpm}$ speed whereas, for Hair tonic, the test was carried out using number 3 spindle and $200 \mathrm{rpm}$ speed. Testing of gel dispersion was determined by measuring the spread diameter of 1 gram of gel between 2 horizontal plates measuring $20 \mathrm{~cm} \times 20 \mathrm{~cm}$ after 1 minute [23].

Table 4: Evaluation of gel and hair tonic formulas

\begin{tabular}{llllll}
\hline Formula & & Evaluation & Tests & \\
\hline & Organoleptic & pH & Viscosity & Homogeneity & Dispersion \\
\hline Gel: FI & brown, fragrant & $6.05 \pm 0.02081666$ & $236.495 \pm 5.398225 \mathrm{mPas}$ & Homogenous & $3.62 \pm 0.076376262 \mathrm{~cm}$ \\
FII & brown, fragrant & $5.91 \pm 0.088881944$ & $257.320 \pm 6.633822 \mathrm{mPas}$ & Homogenous & $3.98 \pm 0.256580072 \mathrm{~cm}$ \\
FIII & brown, fragrant & $5.51 \pm 0.047258156$ & $144.627 \pm$ & Homogenous & $4.45 \pm 0.130766968 \mathrm{~cm}$ \\
& & & $4.733987 \mathrm{mPas}$ & & \\
Hair tonic: FI & brown, distinctive smell, thick & $4.5 \pm 0.040414519$ & $140.000 \pm 20.000 \mathrm{mPas}$ & Homogenous & - \\
FII & brown, distinctive smell, thick & $4.5 \pm 0.075055535$ & $140.000 \pm 10.000 \mathrm{mPas}$ & Homogenous & - \\
FIII & brown, distinctive smell, thick & $4.5 \pm 0,02081666$ & $125.000 \pm 5.773502 \mathrm{mPas}$ & Homogenous & - \\
\hline
\end{tabular}

Note: Gel FI, FII, FIII consisted of respectively 7.5\%, 10.0\%, 12.5\% water fractions, Hair tonic FI, FII, FIII consisted of respectively 7.5\%, 10\%, 12.5\% water fractions 


\section{Hair growth stimulant activity test of gel and hair tonic formula}

Testing of hair growth stimulant activity for gel and hair tonic preparations for pakis munding roots was carried out on 8 male rabbits aged 4-5 mo, healthy without defects and having a body weight of 2-2.5 Kg. The study was carried out based on a modification of the Tanaka et. al method using 4-5-month-old male rabbits, healthy without defects and having a body weight of 2-2.5 $\mathrm{kg}$. The number of rabbits used was obtained from calculations using the Federer formula [33], namely:

$$
(\mathrm{t}-1)(\mathrm{n}-1) \geq 15
$$

Where: $(\mathrm{t})$ number of groups; ( $\mathrm{n}$ ) number of subjects per group.

Before being treated, the test animal was acclimatized for $7 \mathrm{~d}$ so that the rabbit could get used to living in the new environment and treatment to be carried out. Next, one day before testing, the rabbit was shaved on the back to clean and also smeared with $70 \%$ alcohol as an antiseptic. Then the rabbit was rested for $24 \mathrm{~h}[4,17]$. Furthermore, on the back of the tested shaved rabbits, 7 boxes of $2 \times 2 \mathrm{~cm}$ in size were made as to the resting place. Each box is given the following test materials: Box 1: normal control (without treatment), Box 2: positive control (minoxidil 2\%), Box 3: base control (hair tonic or gel bases),
Box 4: hair tonic/gel preparation with $7.5 \%$ water fraction, Box 5: hair tonic/gel preparation with $10 \%$ water fraction, Box 6: hair tonic/gel preparation with $12.5 \%$ water fraction, Box 7: $7.5 \%$ water fraction. The application of ingredients was given every two times in the morning and evening with the amount of $0.5 \mathrm{~g}$ per application. The parameters in the test of hair growth stimulating activity were the length of the test rabbit hair in each box. Tests were carried out for 18 $\mathrm{d}$, with basting on the first day considered to be the 0th day. Hair growth was observed every $3 \mathrm{~d}$, and sampling on the 3rd, 6th, 9th, 12 th, 15th, and 18th days. Samples were taken as many as three of the longest hairs in each box. Then the test rabbit hair was taken, then stored on a flat plane, taped to tape and measured using a caliper. In another group of rabbits, a comparison of the gel and hair tonic was carried out in which one more box was added to the rabbit hair tonic, namely the box for a gel with a concentration of $7.5 \%$.

Data obtained from the measurement results were made of tables and diagrams. For the measurement of the effect of the hair tonic formula, for example, data was obtained (table 5) and illustrated in fig. 1 and then calculated statistically. Table 5 was data from the results of rabbit hair length measurements for formula hair tonics whereas fig. 1 and fig. 2 respectively showed hair growth stimulant activity test of Gel and Hair tonic formula.

Table 5: Rabbit hair length measurements for formula hair tonics

\begin{tabular}{|c|c|c|c|c|c|c|}
\hline \multirow[t]{2}{*}{ Treatments } & \multicolumn{6}{|c|}{ Measurement of rabbit hair on ...... days $(\mathrm{cm})$} \\
\hline & 3 & 6 & 9 & 12 & 15 & 18 \\
\hline \multirow[t]{3}{*}{ Normal control } & 0.09 & 0.11 & 0.18 & 0.30 & 0.48 & 0.54 \\
\hline & 0.09 & 0.16 & 0.40 & 0.45 & 0.50 & 0.68 \\
\hline & 0.10 & 0.20 & 0.36 & 0.56 & 0.69 & 0.70 \\
\hline Mean & 0.093333 & 0.156667 & 0.313333 & 0.436667 & 0.556667 & 0.64 \\
\hline SD & 0.005774 & 0.045092 & 0.117189 & 0.130512 & 0.115902 & 0.087178 \\
\hline \multirow[t]{3}{*}{ Negative control } & 0.30 & 0.38 & 0.42 & 0.55 & 0.58 & 0.60 \\
\hline & 0.41 & 0.51 & 0.61 & 0.76 & 0.96 & 1.05 \\
\hline & 0.28 & 0.58 & 0.61 & 0.70 & 1.00 & 1.06 \\
\hline Mean & 0.33 & 0.49 & 0.546667 & 0.67 & 0.846667 & 0.903333 \\
\hline SD & 0.07 & 0.101489 & 0.109697 & 0.108167 & 0.231805 & 0.262742 \\
\hline \multirow[t]{3}{*}{ Positive control } & 0.46 & 0.98 & 1.10 & 1.35 & 1.59 & 1.675 \\
\hline & 0.41 & 1.17 & 1.27 & 1.55 & 1.99 & 2.04 \\
\hline & 0.19 & 0.20 & 0.22 & 0.38 & 0.46 & 0.68 \\
\hline Mean & 0.30 & 0.783333 & 0.863333 & 1.093333 & 1.346667 & 1.465 \\
\hline SD & 0.155563 & 0.514036 & 0.56359 & 0.625806 & 0.793494 & 0.7039 \\
\hline \multirow[t]{3}{*}{$7,5 \%$ water fraction } & 0.13 & 0.30 & 0.56 & 0.85 & 1.00 & 1.24 \\
\hline & 0.47 & 0.66 & 0.72 & 0.75 & 0.83 & 1.00 \\
\hline & 0.48 & 0.85 & 1.14 & 1.27 & 1.36 & 1.44 \\
\hline Mean & 0.356667 & 0.603333 & 0.806667 & 0.956667 & 1.063333 & 1.226667 \\
\hline SD & 0.196299 & 0.279344 & 0.299555 & 0.275923 & 0.270617 & 0.220303 \\
\hline \multirow{3}{*}{ Hair tonic ( $7.5 \%$ fraction) } & 0.15 & 0.22 & 0.465 & 0.58 & 0.635 & 0.65 \\
\hline & 0.30 & 0.48 & 0.93 & 1.70 & 2.00 & 2.13 \\
\hline & 0.26 & 0.39 & 0.42 & 0.50 & 0.57 & 0.90 \\
\hline Mean & 0.236667 & 0.363333 & 0.595 & 0.926667 & 1.068333 & 1.226667 \\
\hline SD & 0.077675 & 0.132035 & 0.265094 & 0.67092 & 0.807501 & 0.792233 \\
\hline \multirow[t]{3}{*}{ Hair tonic (10.0\% fraction) } & 0.34 & 0.67 & 1.2 & 1.22 & 1.47 & 1.58 \\
\hline & 0.19 & 0.21 & 0.40 & 0.44 & 0.53 & 1.18 \\
\hline & 0.29 & 0.30 & 0.34 & 0.48 & 0.53 & 0.83 \\
\hline Mean & 0.273333 & 0.393333 & 0.646667 & 0.713333 & 0.843333 & 1.196667 \\
\hline SD & 0.076376 & 0.24379 & 0.480139 & 0.439242 & 0.542709 & 0.375278 \\
\hline \multirow[t]{3}{*}{ Hair tonic (12.5\% fraction) } & 0.45 & 0.585 & 0.61 & 1.33 & 1.80 & 2.27 \\
\hline & 0.20 & 0.33 & 0.35 & 0.53 & 0.68 & 1.32 \\
\hline & 0.26 & 0.30 & 0.31 & 0.50 & 0.55 & 0.68 \\
\hline Mean & 0.303333 & 0.405 & 0.423333 & 0.786667 & 1.01 & 1.423333 \\
\hline SD & 0.130512 & 0.156605 & 0.162891 & 0.470779 & 0.687241 & 0.800021 \\
\hline
\end{tabular}

\section{Statistical analysis}

The following was an example analysis with statistical methods for hair tonic.

\section{Hair tonic}

a. Normality test

Objective: to determine the normality distribution of the average rabbit hair length.
Hypothesis: Ho: the distribution of the average hair length of a normal rabbit

H1: the average distribution of rabbit hair length is not normal

$\alpha: 0.05$

Example of Test of normality Shapiro Wilk is shown in table 6 


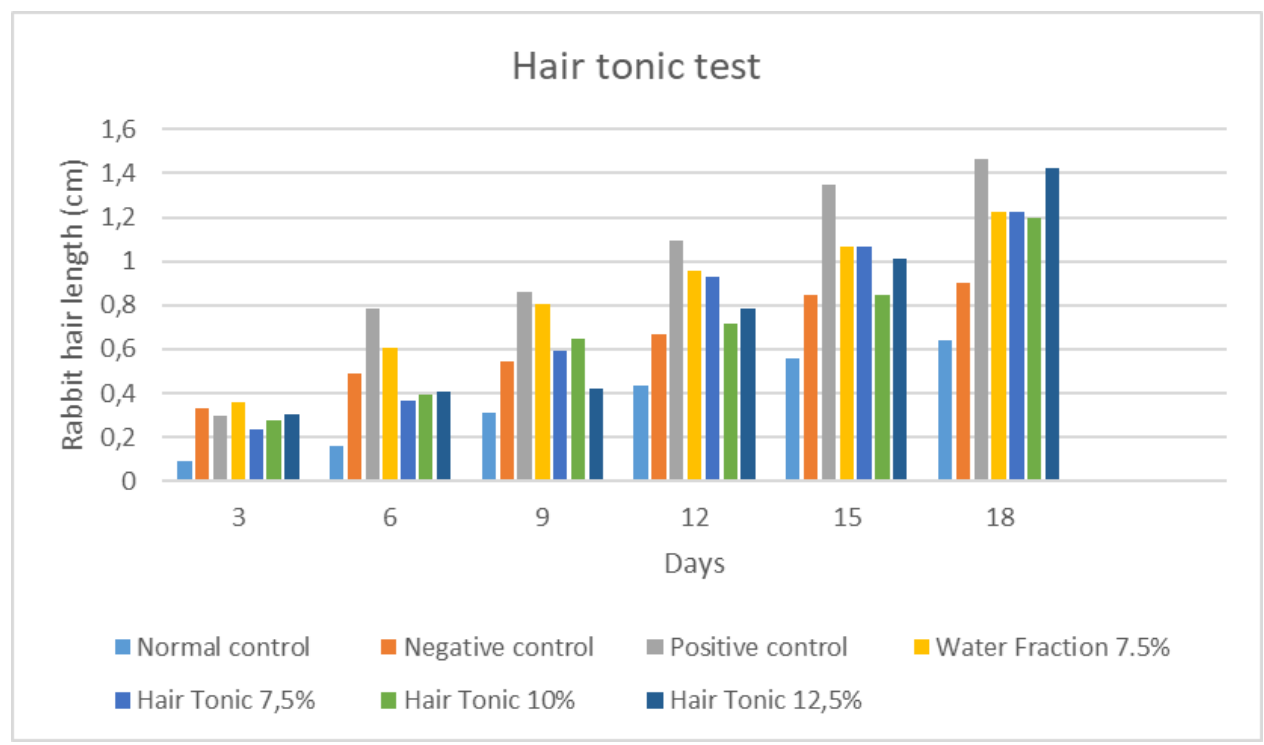

Fig. 1: Hair tonic formula test

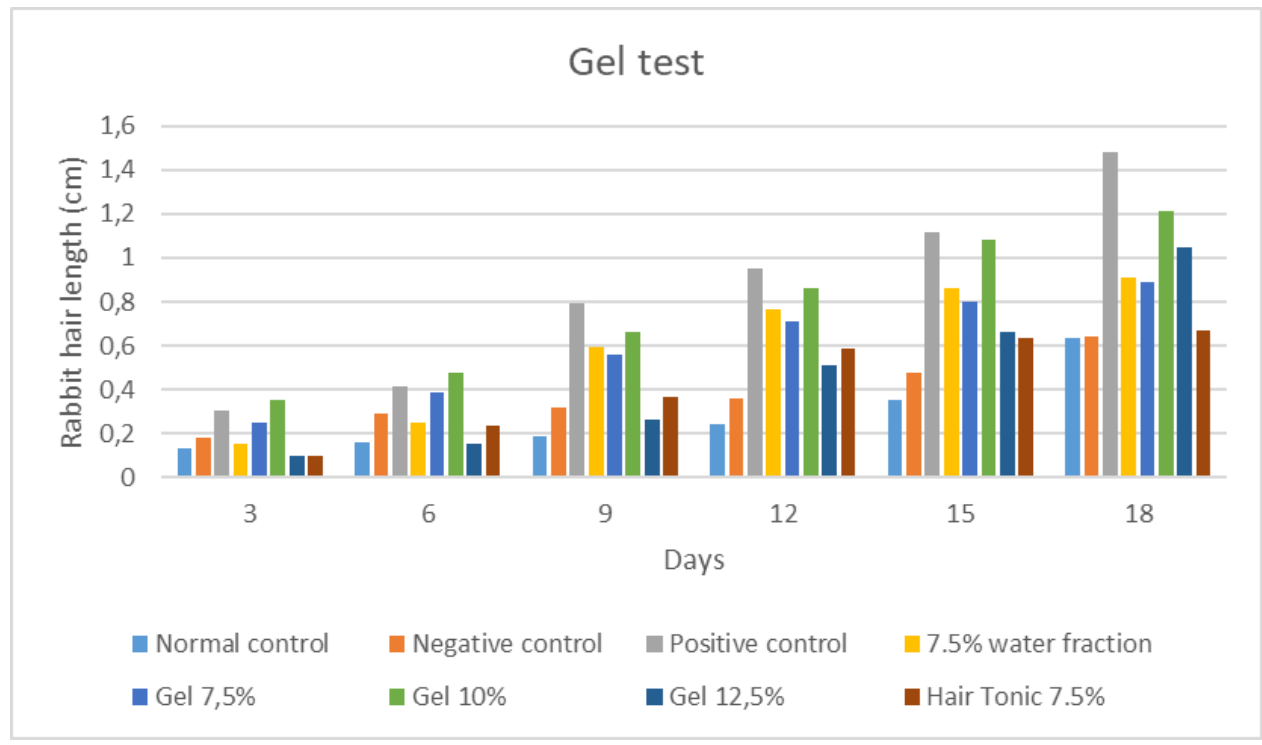

Fig. 2: Gel formula and comparison test

Table 6: Test of normality

\begin{tabular}{|c|c|c|c|c|c|c|c|}
\hline & & Kolmogorov & - & Smirnov $^{a}$ & Shapiro & - & Wilk \\
\hline & Treatment & Statistic & df & Sig. & Statistic & df & Sig. \\
\hline \multirow[t]{7}{*}{ Hair length } & Normal control & .165 & 6 & $.200^{*}$ & .950 & 6 & .740 \\
\hline & Negative control & .171 & 6 & $.200^{*}$ & .959 & 6 & .815 \\
\hline & Positive control & .151 & 6 & $.200 *$ & .965 & 6 & .859 \\
\hline & Fraction & .148 & 6 & $.200 *$ & .978 & 6 & .942 \\
\hline & Hair tonic $7.5 \%$ & .206 & 6 & $.200^{*}$ & .928 & 6 & .566 \\
\hline & Hair tonic $10.0 \%$ & .141 & 6 & $.200^{*}$ & .970 & 6 & .889 \\
\hline & Hair tonic $12.5 \%$ & .256 & 6 & $.200 *$ & .901 & 6 & .378 \\
\hline
\end{tabular}

*This is a lower bound of the true significance

aLilliefors Significance Correction

Criteria: Ho was rejected if the significance value was $<0.05$

Ho was accepted if the significance value is $>0.05$

Conclusion: Ho is accepted, so the data on the average rabbit hair length of each group was normally distributed. b. Homogeneity Test

Objective: to find out the similarity of variants from the data of the average rabbit hair length

Hypothesis: Ho: data on average rabbit hair length varies homogeneously

H1: Data on average rabbit hair length was not homogeneous $\alpha: 0.05$ 


\section{Test statistics: Levene Statistics}

Criteria: Ho was rejected if the significance value was $<0.05$

Ho was accepted if the significance value was $>0.05$

Conclusion: Data on average rabbit hair length on ethanol extract testing varied homogeneously

c. ANOVA Test

Objective: to find out the significant difference of the average rabbit hair length for each group

Hypothesis: Ho: There is no significant difference from the average rabbit hair length for each group

H1: There was a significant difference from the average rabbit hair length for each group

$\alpha: 0.05$

Test statistics: ANOVA

Criteria: Ho was rejected if the significance value is $<0.05$

Ho is accepted if the significance value is $>0.05$

Conclusion: There was no significant difference from the average rabbit hair length for each group

With the same calculation applied to the gel formulation, it was found statistically that the hair tonic formula with $12.5 \%$ water fraction, Gel formula with $10.0 \%$ water fraction was the best application and there was no significant difference between the formula of hair tonic and gel.

\section{Irritation test}

An irritation test was performed to determine the reaction caused by the preparation after the preparation was applied to the skin. Based on the results of the study, there was no irritation reaction on the skin when the preparation was applied on the first day. However, after the application was applied twice a day until the 6th day, there was a reddish color on the skin part which was given by negative control of gel formula. The reddish color started to slightly disappear after the ninth day. The reddish was thought to be due to the presence of Gel excipients such as triethanolamine which slightly irritate the skin. Erythema was indicated by the appearance of redness on the skin and the appearance of the visible wound. While edema was seen from the swollen surface of the skin compared to normal skin. Irritant materials could cause damage to skin cells through chemical work. These chemicals could damage the keratinocyte lipid membranes and then partially penetrate the cell membrane and damage the lysosomes, mitochondria, and core components. Membrane damage activates several mediators such as phospholipase, arachidonic acid (AA) which was converted into prostaglandin and leukotriene, diacylglyceride, platelet activating factor, and also inositide which induces vasodilation and increased vascular permeability. Vasodilation and increased vascular permeability which then showed symptoms of erythema and edema called irritation [34]. This result was not a dangerous irritation test, because it should be noted that basically, the skin sensitivity of experimental animals was slightly different from human skin. Especially rabbit animals whose irritation levels could be easily seen. Irritation index in humans was still uncertain if the value in experimental animals had a mild irritation index [35].

\section{CONCLUSION}

Based on the results of this study, gel and hair tonic formula showed the ability of hair growth. Gel formula containing $12.5 \%$ pakis munding water fraction and hair tonic containing $10.0 \%$ water fraction was the best formula. Statistically, there was no significant difference between hair tonic and gel formulas. Both formulas did not irritate the skin.

\section{ACKNOWLEDGMENT}

We thank PDUPT-KEMRISTEK DIKTI 2018 for supporting and funding this research.

\section{AUTHORS CONTRIBUTIONS}

All the author have contributed equally

\section{CONFLICT OF INTERESTS}

There is no conflict of interest between authors

\section{REFERENCES}

1. Rossi A, Cantisani C, Melis L, Calvieri S. Minoxidil use in dermatology, side effects and recent patents. Recent Pat Inflamm Allergy Drug Discovery 2012;6:130-6.

2. Patil S, Sapkale G, Surwase US, Bhombe BT. Herbal medicines as an effective therapy in hair loss-a review. Res J Pharm Biol Chem Sci 2010;1:773-81.

3. Rahmawati RP, Mustarichie R. Determination of anti-alopecia compounds from water fraction of the angiopteris evecta ( $G$ Forst.) Hoffm. L roots. Drug Invention Today 2018;10:1869-81.

4. Mustarichie R, Hendriani R, Triarini D. Anti-alopecia characteristic of sauropus androgynus (L) merr. ethanol extract and its fractions. Drug Invention Today 2018;10:1302-9.

5. Mustarichie R, Indriyati W, Mukmin A, Ramdhani A. Activity of angiopteris evecta for baldness treatment. J Chem Pharm Res 2016;8:821-30.

6. Tresnawati W. Activities of water, n-hexane, and ethyl acetate fractions of paku munding root (Angiopteris Evecta) as male hair growth stimulator with dosage variation. Thesis. Jatinangor, Indonesia: Jurusan Farmasi UNPAD; 2017.

7. Hatfield G. Encyclopedia of folk medicine. santa barbara, CA: ABC-CLIO; 2004.

8. Amin J, Simamora ELP, Anwar E, Djajadisastra J. Green tea (Camellia sinensis, L.) ethanolic extract as hair tonic in nutraceutical: physical stability, hair growth activity on rats, and safety test. Int J Pharm Pharm Sci 2014;6:94-9.

9. Nabi SAA, Sheraz MA, Ahmed S, Mustaan N, Ahmad I. Pharmaceutical gels: a review. RADS-JPPS 2016;4:40-8.

10. Rathod H, Mehta D. A review on pharmaceutical gel. Int J Pharm Sci 2015;1:33-47.

11. DepKes RI. How to make simplisia (Indonesian: Cara Pembuatan Simplisia.). Jakarta: Departemen Kesehatan RI; 1985. p. 1-25.

12. Kusuma SAF, Mita SR, Firdayani I, Mustarichie R. Study on the antibacterial activity of fruit extracts of klutuk banana (Musa balbisiana Colla) against shigella dysenteriae ATCC 13313. Asian J Pharm Clin Res 2017;10:220-3.

13. Departemen Kesehatan Republik Indonesia. Indonesian Herbal Pharmacopoeia (Indonesian: Farmakope Herbal Indonesia, Edisi I). Jakarta: Departemen Kesehatan Republik Indonesia; 2008.

14. Mustarichie R, Warya S, Saptarini NM, Musfiroh I. Acute and subchronic toxicities of Indonesian mistletoes dendrophthoe pentandra L. (Miq.) ethanol extract. J Appl Pharm Sci 2016;6:109-14.

15. Baki G, Alexander KS. Introduction to cosmetic formulation and technology, wiley; 2015. p. 447-518.

16. Sekar M, Vishnu Priya N, Ramesh R, Suresh Kumar G, Divya Bharati A, Abidha afsha S. Formulation and evaluation of hair tonic from Ziziphus jujuba leaf extract. J Pharm Chem Biol Sci 2016;6:447-54

17. Tanaka S, Saito M, Tabata M. Bioassay of crude drugs for hair growth promoting activity in mice by a new simple method. Planta Med 1980;Suppl:84-90.

18. BPOM RI. Non-clinical toxicity test guidelines in in vivo (Indonesian: Pedoman Uji Toksisitas Nonklinik Secara In vivo). Jakarta: Badan Pengawas Obat dan Makanan Republik Indonesia; 2014.

19. Lane DM. Analysis of variance. Available from: http://onlinestatbook.com/2/analysis_of_variance/intro.html [Last accessed on 12 Feb 2019]

20. Gastwirth JL, Gel YR, Miao W. The impact of levene's test of equality of variances on statistical theory and practice. Statistical Sci 2009;24:343-60.

21. Huddleston JG, Willauer HD, Swatloski RP, Visser AE, Rogers $\mathrm{RD}$. Room temperature ionic liquids as novel media for 'clean' liquid-liquid extraction. Chem Commun 1998;0:1765-6. Doi:10.1039/A803999B. 
22. Aiyalu R, Govindarjan A, Ramasamy A. Formulation and evaluation of topical herbal gel for the treatment of arthritis in the animal model. Brazilian J Pharm Sci (BJPS) 2016;52:494-507.

23. Misal G, Dixit G, Gulkari V. Formulation and evaluation of herbal gel. Indian J Natl Prod Res 2012;3:501-5.

24. Dantas MGB, Reis SAGB, Damasceno CMD, Rolim LA, RolimNeto PJ, Carvalho FO, et al. Development, and evaluation of stability of a gel formulation containing the monoterpene borneol. Sci World J 2016. http://dx.doi.org/10.1155/2016/ 7394685.

25. Mincea MM, Lupsa IR, Cinghita DF, Radovan CV, Talpos I, Ostafe V. Determination of methylparaben from cosmetic products by ultra performance liquid chromatography. J Serb Chem Soc 2009;74:669-76.

26. Krongrawa W, Limmatvapirat S, Pongnimitprasert N, Meetam $P$, Limmatvapirat C. Formulation and evaluation of gels containing coconut kernel extract for topical application. Asian J Pharm Sci 2018;13:415-24.

27. Kasar PM, ASAR*, Kale K, Phadtare DG. Formulation and evaluation of topical antifungal gel containing itraconazole. Int J Curr Pharm Res 2018;10:71-4.

28. Fiolet AS, Jandot E, Doucey P, Cretet C, Brunel C, Pivot C. Longterm stability of gentamicin sulfate-ethylenediaminetetraacetic acid disodium salt (EDTA-Na2) solution for catheter locks. J Pharm Anal 2018;8:386-93.

29. Sharma M, Bhowmick M, Pandey GK, Joshi A, Dubey B. Formulation and evaluation of hair gel for the treatment of chronic inflammatory disorder seborrheic dermatitis. Int J Pharm Res Sci 2013;2:33-41.

30. Rifkia V, Jufri M, Munim A. Hair growth promoting activity of Nothopanax scutellarium merr. Leaves J Young Pharm 2017;9:436-40.

31. Indriaty $\mathrm{S}$, Indrawati $\mathrm{T}$, Taurhesia $\mathrm{S}$. Formulation and test activities of hair tonic with a combination of the aqueous extracts of Aloe Vera and licorice (Glycyrrhiza glabra). Pharmaciana 2018;8:33-42.

32. Kaur LP, Guleri TK. Topical gel: a recent approach for novel drug delivery. Asian J Biomed Pharm Sci 2013;3:1-5.

33. Charan J, Kantharia ND. How to calculate sample size in animal studies? J Pharmacol Pharmacother 2013;4:303-6.

34. Lu F. Lus basic toxicology: fundamentals, target organs, and risk assessment. 4th Ed. London: Taylor and Francis, New Fetter Lan; 2002. p. 209-20.

35. Barel AO, Paye M, Maibach HI. TMMarcel Dekker, Inc. New York: BaselHandbook of Cosmetic Science and Technology, New York: Marcel Dekker, Inc; 2001. p. 35, 95, 107, 253. 